\title{
Johannes Hartig, Eckhard Klieme, Detlev Leutner (eds): Assessment of Competencies in Educational Contexts
}

\author{
Hogrefe \& Huber Publishers, 2008, 356 pp, hardcover; ISBN: \\ 978-0-88937-297-9 (€39.95)
}

Slavenka Jankovic

Published online: 4 June 2009

(C) Springer-Verlag 2009

The assessment of competencies nowadays plays a key role in optimizing educational processes and improving the educational system.

The book Assessment of Competencies in Educational Contexts is a comprehensive overview about current theoretical, psychometric, and practical issues important for the assessment of competencies in different educational settings. It was written by 30 leading researchers, experts in the field of educational and psychological research, from several European countries and the USA.

The first part of the book "Theoretical Perspectives and Developmental Models" covers different concepts of competencies in educational contexts, current challenges in the assessment of competencies, as well as developmental models, changes, and constraints.

The second part of the book "Psychometric Modeling" consists of four chapters: "Psychometric Models for the Assessment of Competencies"; "Explanatory Item Response Models"; "Linking Competencies in Horizontal, Vertical and Longitudinal Settings and Measuring Growth"; and "Reporting Test Outcomes Using Models for Cognitive Diagnosis." Practical issues such as test construction, reporting of scores, and computer-based assessment are described in detail.

The third part of the book "Assessment Methods and Technology" is related to the measurement of competencies with emphasis on the usage of the Internet and computer technology as tools for competence assessments.

The last, fourth part of the book "Large-Scale Assessment for the Monitoring of Educational Quality" deals with different designs of large-scale assessments, the main characteristics of the educational standards in Germanspeaking countries, fair comparisons of competencies assessed in different schools, and principles of assessment and Internet-based feedback of test results.

The book is valuable for anybody dealing with assessment of competencies in educational settings. It is intended for educational researchers, policy makers, teachers, school administrators, and all others interested in current methods of pedagogical and psychological evaluation.

\footnotetext{
S. Jankovic $(\bowtie)$

Centre School of Public Health and Institute of Epidemiology,

Faculty of Medicine, University of Belgrade,

Visegradska 26,

11000 Belgrade, Serbia

e-mail: slavenka@eunet.rs
} 